\title{
The Application of English Translation Technology in the Field of Elec- tronic Information
}

\author{
Jing Zheng* \\ School of Foreign Studies, Jiangxi Science and Technology Normal University, Nanchang 330038, Jiangxi, China
}

\begin{abstract}
Translation is an important language skill. Due to the progress in the society after the development in science and technology, higher requirements for English translation have been put forward. With the progress in science and technology, the wide range of technological exchange and the speed of renewal, electronic information technology plays a more import role in modern society. At the same time, people also seek to share and exchange the latest electronic information technology more quickly and more accurately. Therefore, i English translation technology is currently the focus of the electronic information field. This paper discusses the function of the technology of English translation, the function of the Internet resource and the search engine, besides the use of the method and the technique. It is proved that the technology of English translation plays a pivotal role in the development of modern electronic information.
\end{abstract}

Keywords: Electronic information, network resources, search engine, translation software, translation.

\section{INTRODUCTION}

Currently, the electronic information industry has shown rapid development, especially network $[1,2]$ technology and computer technology. Moreover, some advanced information technology is widely adopted in every aspect of social life. to address the role and application of English translation technology in the field of electronic information; how to effectively use English translation technology to enhance the efficiency of translation, and how to use information technology to assist English translation. The study briefly introduced the process of translation using information technology to solve some of the problems in translation and summarized some of the skills involved in the process. Through the analysis of the characteristics of professional English, the article classified the vocabulary. Furthermore, through the analysis of English translation technology, the translation strategies of free translation, transliteration, semi - translation and translation have been summarized. In 2013, China's scale of electronic information manufacturing increased to 11. $3 \%$, which was 1.6 percentage points higher than the average level. Over the same period industrial revolution, total profits and taxes [4] accounted for overall industrial production of $9.1 \%, 6.6 \%$ and $4.0 \%$, respectively. The growth rate of total profits and taxes reached $21.1 \%$ and 19 . $1 \%$, respectively, which were significantly higher than the average level of industry's total profit and tax of $12.2 \%$ and 11. $0 \%$, respectively. Electronic information manufacturing

*Address correspondence to these authors at the School of Foreign Studies, Jiangxi Science and Technology Normal University, Nanchang 330038, Jiangxi, China; E-mail: yctk520@163.com maintained its leading position in the industrial economy, leading the country towards development [5] as shown in Fig. (1).

\section{THE FEATURES OF ENGLISH TRANSLATION TECHNOLOGY IN THE FIELD OF ELECTRONIC INFORMATION}

\subsection{The Nature of No Person}

The notable feature of English in electronic information engineering is that there are often no personal pronouns in the sentence. It describes and discusses mostly the scientific discovery or the scientific facts related to electronic information engineering domain, which is objective in nature. Although technology is meant for the people, and the human is the initiator, however, scientific and technological literature are mainly the result of scientific and technological activities $[6,7]$ or are based on the natural law and objective things, rather than the actors. Therefore, most of the sentences have no personal pronouns. A sentence generally requires the use of direct or relative pronouns as the subject.

\subsection{Accuracy and Rigor}

As the language of the field of electronic information is objective, therefore, people's attitudes towards science and technology reflected through the language also seem to be objective. Therefore, So the subjective consciousness of the electronic information specialty English in admixed individuals, and statement of objective things is objectively accurate [8] tone more formal, and the logic of the theory is also very strict. Unlike other literary works rich in rhetoric and written by using a variety of writing techniques, which do not allow the reader to have diverse imagination and understanding. 


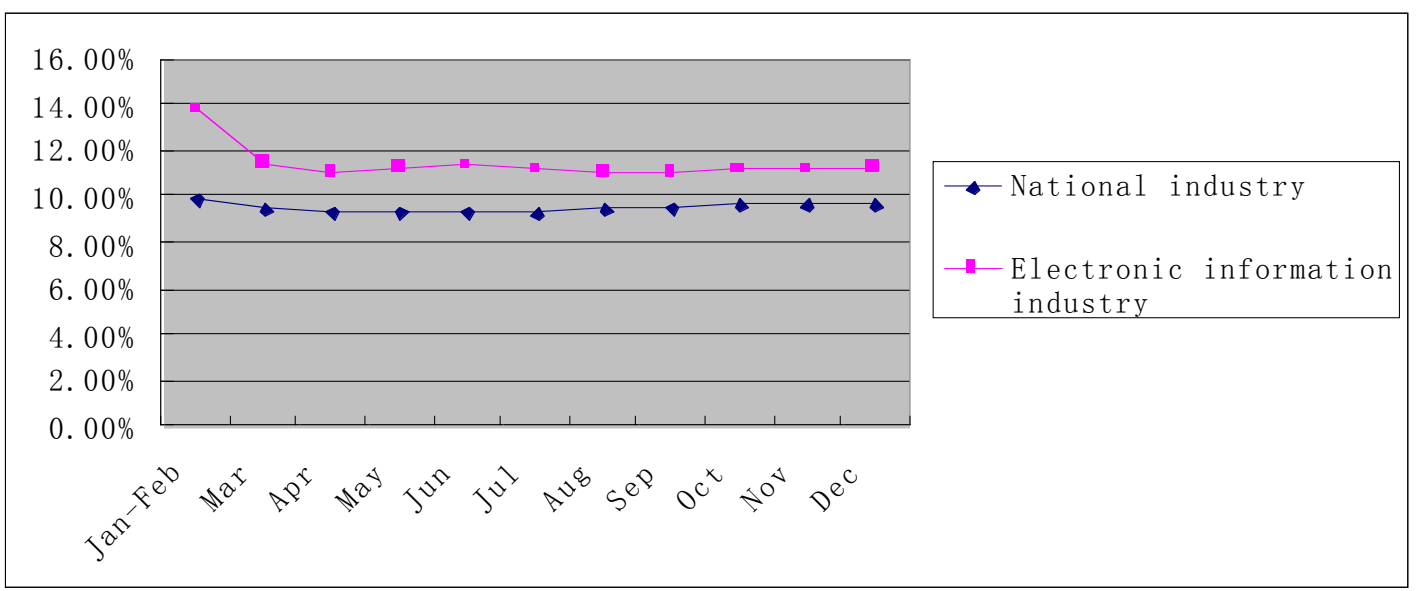

Fig. (1). 2013 China electronics manufacturing industry and the national industrial added value of the cumulative growth rate contrast.

\subsection{Strong Professional}

As used in science and technology, English used in the field of electronic information delivers theoretical knowledge, and is highly specialized, which is reflected through vocabulary, statements and so on. Vocabulary [9] is the basic element of the sentence, Therefore, English used in the electronic information engineering is full of professional vocabulary, in addition to some common vocabulary.

\section{BASIC ENGLISH TRANSLATION TECHNOLOGY}

\subsection{Free Translation}

Free translation is a translation method [10] based on translating technical meaning of the original terms and the meaning of the words used in the same language. Free translation aims to provide accurate translation of terms closer to the original meaning of the expressions. The relationship between the recipient and the target text should be the same as the relationship between the original recipient and the original text, so that the meaning and the scientific concept [11] become clear, to avoid misunderstanding. In professional English of electronic information engineering, there are a lot of technical vocabulary aspects which are either derivatives, or compounds, etc. These words can be translated into the corresponding terms according to the actual meaning of the original word. In this way, these translations can make the concept clear and easy to understand, which becomes easier for the reader to comprehend and remember.

\subsection{Transliteration}

Under some special circumstances, some words cannot be translated by translation, free translation or other translation methods. In this case, A, a word can be accepted and approved by the target language and is widely circulated, and can be comprehended according to pronunciation. These words generally include words used to express special things, inventions, principles or units of measurement.

\subsection{Half Free Translation}

In professional English of electronic information engineering, in order to let the reader or professionals easily record or recognize a number of technical vocabulary items, their translation is necessary. Therefore, translation is very important.

\section{THE APPLICATION OF ENGLISH TRANSLATION TECHNOLOGY IN THE FIELD OF ELECTRONIC INFORMATION}

\subsection{Development of English Translation Software}

In the last few years, there have been many kinds of translation software, which can be divided into two categories: electronic dictionary and machine translation software. In addition to the traditional function of the dictionary, the electronic dictionary has the capacity to provide the meaning of additional words. The electronic dictionary can be divided into portable [12] electronic dictionary (such as Wenquxing) and dictionary application software (such as Kingsoft) used on PC. The dictionary on the PC software also has screen timely capturing function. For reading electronic documents in English, it is very convenient for using the search function to locate the meaning of unfamiliar words. Compared with the traditional paper dictionary, electronic dictionary provides real pronunciation, vocabulary and other functions like automatic search. Therefore, with the popularization of computer and the decline in the price of electronic equipment, there will an inevitable trend that electronic dictionary will replace the traditional dictionary. In recent years, the development of machine translation software has been very rapid. It is estimated that there are more than 1000 kinds of translation software in the world, and there are more than 20 kinds of machine translation software in China. According to its application, the software can be divided into PC products and online application products, and online application products are free of cost. China is famous for offering applications in PC translation software: CCID hyt, Kingsoft FastAIT, Orient Express, elegant letter, etc.

\subsubsection{Prospects and Development of English Translation Software}

The concept of machine translation was first proposed byB G, a French scientist, in the early 30's of the twentieth century. In 1946, with the advent of electronic computers, two engineers A. D. Booth \&W. Weaver A first proposed the idea of using of computer for translation, and in 1949 pub- 
lished a translation memorandum. Although the concept of machine translation was put forward in 1946, the author was of the view that the machine translation had not made substantial progress and therefore, cannot replace the manual translation. At present, the translation software in China only performs literal translation, and it is still a challenge for technology to make substantial progress in the process of PC translation. Because machine translation is related to computer science, mathematics, linguistics and other disciplines, therefore, to think of short term development in all the translation softwares is not realistic. In comprehensive terms, the translation software should have the following functions: The first is specialization. The translation software should be clear in terms of its translation domain, which can greatly improve the translation accuracy. Secondly, it must have intelligence, which is required for translating the contextual meaning of the word; the translation software should have the function of translation memory so that it can automatically repeat the translation of similar paragraphs and so on. The third function is to strengthen the learning ability and expand the memory. Translation software should be more flexible in terms of strengthening user's translation habits and learning. Machine translation not only processes text problems, but processes knowledge based problems, that cannot be solved overnight. It is a long process of accumulation, requiring a long period of time and is inseparable from people's active participation.

\subsubsection{How to Use Translation Software to Aid English Translation?}

Although the quality of machine translation is still poor, it can also perform a lot of translation work to improve the efficiency of translation. The question is how should machine translation software be used to aid the translation work? Translation tasks may vary, but the following aspects should be considered: One is the selection of appropriate translation software. Translation softwares available in the market $\mathrm{f}$ have different emphases and functions, therefore, appropriate translation software should be chosen according to the specific requirements of translation. Second is the initiative of using a combination of softwares to improve their intelligence. After selecting a software, the software should be used reasonably, appropriately maximizing the rate of translation through the software according to the function provided by the software. As most of the translation softwares have a learning function, it should be used to improve "intelligence" of the software. Third is the establishment of personalized thesaurus which should be used in the process of translation to enrich and improve one's own personalized thesaurus.

\subsection{The Application of English Translation Technology in Network Resource Acquisition}

\subsubsection{The Status Quo of the Translation Industry Contin- ues}

Translation is the process which can be carried out online, which involves the translation of social transformation and upgrade. Many people are engaged in translation and most of them are a member of some translation agency or are involved in the printing of documents. The team, is not large. A translation team comprising of more than 10 individuals is considered large. The main business objects are all engaged in the business of foreign government, trade and other units, many translation agencies are anchored a few characteristics of the unit. At the same time and to do other copy related business, which means that once the Print Club dependent unit or the termination of the cooperation, may the print business this stop, even in the face of closing.

Internet is used by more than $90 \%$ of the print clubs as the tool of file transferring and searching in Baidu. Moreover, other search engines are also used to "translate" the keywords, and search results in the translation software. Basically there have been no enterprise for advertising translation. Some other translation related business websites and enterprises in the industry only aim to promote their propaganda beneficial for their business. The translation industry is also being transformed, but most of the enterprises engaged in the translation do not have the ability to be transformed or modified. There have been no online translation company that have made the industry a part of oligopoly.

The demand of online translation of manuscripts is more by government enterprises, communities and people as people are more engaged in foreign business, therefore, the demand of manual translation is not significant. / According to the demand, online translation of the downstream demand is government, enterprises, communities and individuals of some document manuscripts, this part of the population are engaged in foreign related business, population is not a lot of translation are rigid demand, the market how much? The Canton Fair has engaged in a number of personnel in the translation work. From the network software it was observed that until November 2014, the number of users of Youdao dictionary reached 3.5 billion, with most of the users only registered at that time and did not continue. At least ten millions of regular users are required for machine translation to complete the translation work.

In addition, due to lack of the industry of professional translation, such as computer English, most translation agencies cannot do, so for the translation professional translation talents is valuable, but an industry which can each industry configuration of a professional translation and the translation not translation file of other industries? This is the translation industry is difficult to appear a large number of enterprise is one of the reasons.

\subsubsection{Use of English Translation Technology to Obtain Network Resources}

"Faithfulness" and "expressiveness" have become recognized today as two criteria of English translation, namely, "faithfulness" and being "smooth", in which the former asks to convey the correct meaning of the original content, while the latter suggests that the language must be smooth and easy, in line with the Chinese standard [3]. English and Chinese languages have different style of rhetoric, different social background, thinking patterns and different ways of expression etc. Therefore, some sentences cannot be properly translated only grammatically, as they also require logic or professional content to be determined. A person who masters professional knowledge acquires knowledge limited to the respective field; therefore, he/she cannot be expected to be 
particularly familiar with history and geography, customs and living habits. Therefore, the use of translation technology to obtain information through network resources is the shortcut to solve these problems. Wiki. Org (HTTP), provides the background knowledge of some characters, and information regarding all kinds of appliances can be found in the Wikipedia (zh: Wikipedia). Information regarding, he historical background can be obtained through the network to find the authenticity of the news media (such as the New York Times: http: www. Nytimes.Com) news report. Thorough understanding of news background enables us to translate more accurately by conveying the original meaning of the expression from author's standpoint.

\subsection{The Function of English Translation Technology in Search Engine}

\subsubsection{Translation of traditional English}

Because of different characters used in English and Chinese, they have different morphology and syntax, and have different ways of expression. Each language has its own inherent features and performance. Therefore, people translate often according to their own translation experience of the sentence structure of English or Chinese as well as the understanding of the text, with the help of a translation dictionary. However, the continuous development in science and technology continuously increases the range of vocabulary with new words appearing every day. These words cannot be included in the traditional dictionary at the time of their coinage. Therefore, the understanding and translation of these words often render translators unfamiliar with their meaning. In fact, search engines can easily find more accurate translation of such vocabulary items.

\subsubsection{Auxiliary Search Engine Aided by English Transla- tion}

The development of Internet and search engine is inseparable, as development in every search engine is brought about through Internet. The search function has become one of the largest Internet applications. In the translation of English translation, translation helps to search the reference of the existing translated literature in order to improve the translation efficiency and accuracy, especially the specific meaning of some new words from the dictionary as well as some abbreviations. The method is described below. For instance, for a word "netizens", on the basis of prior experience, it can be inferred that the word may contain the combinations "net", therefore, in the common search engines (such as Google: www.Google.Com, MSN Search: http: search. Msn.Com) intervening (in the net and netizen with spaces "net name" key cut, its specific meaning see documentation for each search engine) to search, in search results can often find the correct translation. Here take Search MSN as an example, in search results of second pages from second lines of the correct translation: "Internet users (netizen)". With the characteristics of the word is our translation difficulties, these words are often not included in traditional dictionaries, but in most of the literature, they have prescriptive translations, that can be referred for the translation. For instance, if the expression "League branch secretary", is to be translated, it can be speculated that it may contain the word League, therefore, in the search engine intervention, the phrase "League branch secretary" is typed and searched. MSN Search displays the search results on the first page in the first row: League branch secretary League branch secretary. In addition, specific meanings of acronyms are often not in the traditional dictionary, therefore for this purpose also, network resources can be utilized. With reference to the existing translation of the acronym explained, the background knowledge of the words representing institutions and professional vocabulary can be searched. Search engine, more than just a valuable simple application used in the process of translation, it has a great potential of mining. On the network resources, either efficient or non-efficient, search results are not entirely accurate, but can provide some useful reference, that application needs to decide according to its own judgment whether to adopt.

\section{CONCLUSION}

Translation is a process of translating one language into another. Language in terms of content and form will continue to be enriched and updated, and the network resources and search engine by people also conforms to this feature. At the same time, in order to shorten the translation process and improve translation efficiency, it also calls for the development of the translation software to make it more intelligent. On the basis of mastery of certain professional knowledge, a certain strategy is adopted, and the target translation can be received by different readers or recipients. But the field of electronic information engineering is always at a stage of continuous renewal and development, which gives rise to the emergence of new things and ideas and consequently of new words. However, a large number of common words to express new things are still used. Moreover, technical vocabulary of Fan Wai continues to expand, and vocabulary 1 also continues to increase, for the translation of these words, improvement in the system is required. With the rapid development in electronic information technology, English translation technology will be applied in wider range. Integration of English translation technology and electronic information technology assist in the development of the electronic information industry, further making use of the advantages of electronic information to improve English translation, and the alternate/turning technique is more diverse.

\section{CONFLICT OF INTEREST}

The author confirms that this article content has no conflict of interest.

\section{ACKNOWLEDGEMENTS}

Declared none.

\section{REFERENCES}

[1] Q. Han, "English and Chinese translation of science and technology translation tutorial," Shanghai Foreign Language Education Press, vol. 05, pp. 1-15, 2010.

[2] Q. Wu, and G. Feng, "Student at the Beijing Foreign Studies University," Shanghai English Education Press, vol. 02, pp. 101-115, 2009.

[3] B. Susan, "Translation Studies," New Accents, vol. 03, pp. 1-15, 2008. 
[4] L. Hickey, "The Pragmatics of Translation," Shanghai Foreign Education Press, vol. 06, 2011.

[5] L. Venuti, "Rethinking Translation :Discourse, subjectivity and ideology," Wuhan press, vol. 12, no. 02, 2012.

[6] A. Hazem, "Bilingual lexicon extraction from comparable corpora as meta search," in Proceedings of the 4th Work-shop on Building and Using Comparable Corpora, vol. 12, no. 6, pp. 35-43, 2011.

[7] R. E Quan, "Analysis of translation revision: Contrastive corpus research on native English and Chinese translation," Proceedings of XVIII FIT World Conference, Shanghai, 2008.

[8] I. Skadina, "Collection of compare corpora for under-resourced languages. Proceeding of the 2010Conference on Human Language Technologies," in The Baltic Perspective Proceedings of the Fourth International Conference Baltic HLT, vol. 12, pp. 161-168, 2010.
[9] A. M. McEnery, and R. Z. Xiao, "Parallel and comparable corpora : What are they up to Incorporating Corpora:Translation and the Linguist Translating Europe Clevedon," UK: Multilingual Matters, 2007.

[10] A. Eisele, and J. Xu, "Improving machine translation performance using compare corpora," in Proceedings of the 3rd Workshop on Building and Using Comparable Corpora, vol. 23, pp. 12-20, 2010

[11] G. Braham, "Two ways to use a noisy parallel news corpus for improving statistical machine translation," Proceedings of the 4th Workshop on Building and Using Compare Corpora, vol. 12, pp. 20-27, 2011

[12] A. Hazem, "Bilingual lexicon extraction from compare as meta search," in Proceedings of the 4th Work-shop on Building and Using Comparable Corpora, vol. 12, no. 6, pp. 36-40, 2011.

Received: June 10, 2015

Revised: July 29, 2015

Accepted: August 15,2015

(C) Jing Zheng; Licensee Bentham Open.

This is an open access article licensed under the terms of the (https://creativecommons.org/licenses/by/4.0/legalcode), which permits unrestricted, noncommercial use, distribution and reproduction in any medium, provided the work is properly cited. 